\title{
Transmission of sheep-bovine spongiform encephalopathy to pigs
}

\author{
Carlos Hedman ${ }^{1}$, Rosa Bolea ${ }^{1 *}$, Belén Marín ${ }^{1}$, Fabien Cobrière ${ }^{4}$, Hicham Filali ${ }^{1}$, Francisco Vazquez², \\ José Luis Pitarch ${ }^{1}$, Antonia Vargas ${ }^{1}$, Cristina Acín ${ }^{1}$, Bernardino Moreno ${ }^{1}$, Martí Pumarola ${ }^{3}$, Olivier Andreoletti ${ }^{4}$ \\ and Juan José Badiola ${ }^{1}$
}

\begin{abstract}
Experimental transmission of the bovine spongiform encephalopathy (BSE) agent has been successfully reported in pigs inoculated via three simultaneous distinct routes (intracerebral, intraperitoneal and intravenous). Sheep derived BSE (Sh-BSE) is transmitted more efficiently than the original cattle-BSE isolate in a transgenic mouse model expressing porcine prion protein. However, the neuropathology and distribution of Sh-BSE in pigs as natural hosts, and susceptibility to this agent, is unknown. In the present study, seven pigs were intracerebrally inoculated with Sh-BSE prions. One pig was euthanized for analysis in the preclinical disease stage. The remaining six pigs developed neurological signs and histopathology revealed severe spongiform changes accompanied by astrogliosis and microgliosis throughout the central nervous system. Intracellular and neuropil-associated pathological prion protein $\left(\mathrm{PrPSC}^{\mathrm{SC}}\right.$ deposition was consistently observed in different brain sections and corroborated by Western blot. PrPSc was detected by immunohistochemistry and enzyme immunoassay in the following tissues in at least one animal: lymphoid tissues, peripheral nerves, gastrointestinal tract, skeletal muscle, adrenal gland and pancreas. $\operatorname{PrP}^{\mathrm{SC}}$ deposition was revealed by immunohistochemistry alone in the retina, optic nerve and kidney. These results demonstrate the efficient transmission of Sh-BSE in pigs and show for the first time that in this species propagation of bovine PrPSc in a wide range of peripheral tissues is possible. These results provide important insight into the distribution and detection of prions in non-ruminant animals.
\end{abstract}

\section{Introduction}

Transmissible spongiform encephalopathies (TSE) are chronic neurodegenerative disorders that affect humans and animals and are associated with the accumulation of an abnormal isoform $\left(\mathrm{PrP}^{\mathrm{Sc}}\right)$ of the cellular prion protein $\left(\mathrm{PrP}^{\mathrm{C}}\right)$ in the central nervous system (CNS) [1]. TSE are characterized by spongiform changes in the grey matter accompanied by astrocytosis and microgliosis [2-4]. The new variant of Creutzfeldt-Jakob disease (nvCJD) in humans [5] has been linked with the consumption of bovine spongiform encephalopathy (BSE) contaminated meat or meat products during the BSE epidemic in the UK and elsewhere. Moreover, one BSE natural case in a

\footnotetext{
*Correspondence: rbolea@unizar.es

${ }^{1}$ Veterinary Faculty, Centro de Investigación en Encefalopatías y Enfermedades Transmisibles Emergentes (CIEETE), Universidad de Zaragoza, 50013 Zaragoza, Spain

Full list of author information is available at the end of the article
}

goat in France [6] and another one in the UK [7, 8] have been reported. Sheep and goats can also be experimentally infected using homogenized brain from affected animals as inocula [9-11]. While BSE infection is largely restricted to the nervous system in cattle $[12,13], \operatorname{PrP}^{\mathrm{Sc}}$ is widely distributed in the lymphoid tissues of sheep experimentally infected with BSE [10, 14], suggesting that infected sheep could constitute a secondary and more dangerous source of BSE infection for other species, including humans [15-17].

TSE has not been reported in natural conditions in pigs [18], and there is no evidence of BSE transmission between pigs fed with brain material from cattle [19]. However, despite the existence of a strong transmission barrier, signs of TSE have been reported in pigs challenged simultaneously with BSE-derived material via intraperitoneal, intravenous and intracerebral administration [20-22]. Those studies demonstrated pathological 
changes and $\operatorname{PrP}^{\mathrm{Sc}}$ deposition in the CNS, but reported no evidence of $\operatorname{PrP}^{\mathrm{Sc}}$ distribution in other organs. Given the possible lifting of the European Union's ban on feeding pigs and poultry with animal meal, it is vital that TSE transmission be studied in supposedly resistant species, such as swine, that form part of the human food chain. Pigs are the source of a wide range of food products, and pork is one of the most widely eaten meats in the world. Blood is frequently collected during slaughter for blood sausage production and natural sausage casings are almost exclusively prepared from different parts of the alimentary tract of pigs. The use of pigs as graft donors is also a cause for concern, given a reported case of CJD type 1 in a recipient of a porcine dura-mater graft [23]. It has also been demonstrated that BSE experimentally passaged in sheep (Sh-BSE) homozygous for the $\mathrm{A}_{136} \mathrm{R}_{154} \mathrm{Q}_{171}$ allele of ovine prion protein (PrP) exhibits altered pathobiological properties due to a decreased polymorphism barrier [24]. The virulence of Sh-BSE in transgenic mice expressing porcine [15] and human $\operatorname{PrP}$ $[16,25]$ is enhanced with respect to the original cattle BSE prion isolate.

This study is the first to describe the tissue distribution of $\mathrm{PrP}^{\mathrm{Sc}}$ in pigs experimentally infected with BSE previously passaged in sheep, as well as the clinical and neuropathological consequences.

\section{Materials and methods}

\section{Ethics statement}

All procedures were carried out under Project License COTSA EFA 85/08 and CONCOTSA EFA 205/11 and were approved by the in-house Ethic Committee for Animal Experiments under license PI 13/10 from the University of Zaragoza. All animal experiments were performed in accordance with the Spanish Policy for Animal Protection RD1201/05 and European Union Directive 86/609 for the protection of animals used for experimental and other scientific purposes.

\section{Sheep BSE inoculum}

Sheep BSE isolate (Sh-BSE) was originally derived from a pool of $A R Q / A R Q$ sheep that were experimentally infected by intracerebral inoculation with the BSE agent [26]. This isolate was supplied by the Institut National de la Recherche Agronomique (INRA-Toulouse, France).

\section{Experimental challenge of pigs with sheep BSE}

Eight 8-month old minipigs (1 castrated male and 7 females) from the Instituto Madrileño de Investigación y Desarrollo Rural, Agrario y Alimentario (IMIDRA), were intracerebrally inoculated under general anesthesia. Seven animals were challenged with $0.5 \mathrm{~mL}$ of inoculum consisting of a $10 \%$ homogenate of the Sh-BSE agent in sterile saline solution, administered in a single injection. One animal was challenged with $0.5 \mathrm{~mL}$ of sterile saline solution. The injection site was located $1 \mathrm{~cm}$ lateral to the midline in the frontal region. The trephine was performed with a dental drill and the inoculate administered via a $20 \mathrm{G} \times 2 \frac{3 / 4}{}$ " needle.

\section{Clinical monitoring}

Pigs were monitored daily by animal husbandry staff, and 1-7 veterinary clinical assessments were carried out per week, depending on the stage of the animals.

\section{Tissue sample collection}

Animals were euthanized by exsanguination after intravenous pentobarbital injection (DOLETHALND ${ }^{\circledR}$; $10 \mathrm{mg} / \mathrm{kg}$ ), which was administered on observation of clinical signs suggesting an encephalopathy or the presence of a life-threatening or welfare-compromising disease. Necropsies were conducted systematically and samples collected from the central nervous system (CNS), peripheral nervous system (PNS), lymphoreticular system (LRS), gastrointestinal tract (GIT), skeletal muscles and other tissues. In all cases, tissues samples were collected in duplicate; one sample was stored at $-80^{\circ} \mathrm{C}$ and the other in $10 \%$ formal saline solution.

\section{Histopathology and immunohistochemistry}

For detailed CNS studies, transverse sections of the following areas were selected and stained with hematoxylin and eosin (H\&E): frontal cortex (FC), basal ganglia (BG), lateral frontal cortex (LFC), thalamus (T), hypothalamus (Ht), temporal/parietal cortex (TPC), hippocampus $(\mathrm{HC})$, occipital cortex (OC), mesencephalon (Ms), cerebellum (Cbl), 4 neuronal nuclei [the hypoglossal motor nucleus (HMN); the nucleus of the trigeminal nerve spinal tract $(\mathrm{NTN})$; the olivary nucleus $(\mathrm{ON})$; and the dorsal motor nucleus of the vagus nerve (DMNV)], the reticular formation (RF) of the medulla oblongata (MO), and the cervical (CSC), thoracic (TSC), and lumbar spinal cord (LSC). $\operatorname{PrP}^{\mathrm{Sc}}$ detection was performed in adjacent sections following pretreatment with $98 \%$ formic acid, hydrated and autoclaved to enhance antigen retrieval. After proteinase $\mathrm{K}$ digestion $(4 \mathrm{~g} / \mathrm{mL})$, the sections were incubated with blocking reagent (DAKO) for $10 \mathrm{~min}$ to block endogenous peroxidase activity, as previously described [27]. Next, sections were incubated with the monoclonal primary antibody 2 G11 (1:400) [28] at room temperature (RT) for $1 \mathrm{~h}$. The study of the $\mathrm{PrP}^{\mathrm{Sc}}$ deposition types and distribution pattern were based on the descriptions reported in natural and experimental scrapie, and experimental BSE in sheep [29-31].

Astrocytosis was evaluated using glial fibrillary acidic protein (GFAP) immunostaining, as previously described 
[32], and microglia identified in FC, BG, T, Hc, Cbl, MO and CSC sections by immunohistochemical detection of the active form of a calcium-binding protein, specially expressed in microglia cells (Iba-1). After heat-induced epitope retrieval by pretreatment with citrate buffer (pH 6.0), sections were incubated for $1 \mathrm{~h}$ at RT with the primary anti-GFAP antibody (rabbit polyclonal, 1:500; DAKO) and overnight at $4{ }^{\circ} \mathrm{C}$ with Iba-1 (goat polyclonal 1:600; Abcam), respectively. Sections were subsequently counterstained with hematoxylin.

\section{Western blotting}

Samples were treated with proteinase K, subjected to sodium dodecyl sulfate polyacrylamide gel electrophoresis (SDS-PAGE), and blotted onto membranes according to the Prionics AG (Schlieren, Switzerland) Check $^{\circledR}$ Western BSE test protocol [33], using Sha31 monoclonal antibody (1:8000; Spibio A03212), the Bio-Rad VersaDoc imaging system and Quantity One 1-D Analysis Software (Bio-Rad) for visualization.

\section{IDEXX HerdChek ${ }^{\circledR}$ BSE-Scrapie Antigen Test}

A ligand-based enzyme immunoassay (IDEXX HerdChek ${ }^{\circledR}$ BSE-Scrapie Antigen Test, hereafter referred to as IDEXX), which does not use a PK digestion step, was used to analyze a wide number of samples according to the manufacturer's instructions, using the conjugate for cattle in each sample. Samples $(300 \mathrm{mg})$ were processed as previously described for sheep tissues [34]. The negative cut-off value applied for the bovine conjugate was 0.14 absorbance units.

\section{Data analysis}

Vacuolation, $\mathrm{PrP}^{\mathrm{Sc}}$ deposition, astrocytosis and microgliosis in the CNS were evaluated in the stained sections and scored on a scale ranging from 0 to $5(0=$ not detectable; $1=$ occasional; $2=$ mild; $3=$ moderate; $4=$ severe;
$5=$ extreme). A possible correlation between lesions and immunolabeling in the CNS was evaluated using the non-parametric Spearman's rho measure. $P<0.05$ was considered significant, $P<0.01$ very significant and $P<0.001$ highly significant. Lesion and immunolabeling scores were plotted as a function of the anatomical area, and data expressed as the mean \pm standard deviation.

In peripheral tissues, positive results were scored according to the intensity of $\mathrm{PrP}^{\mathrm{Sc}}$ labeling, and were classified as negative $(-)$, minimal-to-mild $(+)$, moderate $(++)$ or strong $(+++)$.

\section{Results}

Details of incubation period, date of euthanasia, clinical signs and $\mathrm{PrP}^{\mathrm{Sc}}$ detection by IHC and WB in the brains of all animals are provided in Table 1.

\section{Clinical signs and disease course}

One pig (P-7) was euthanized for preclinical analysis at 42 weeks post-injection (wpi). The remaining inoculated animals developed clinical signs between 77 and $109 \mathrm{wpi}$ $[100 \pm 12.9 \mathrm{wpi}$, mean and standard error of the mean (SEM)]. Behavioral changes were the first clinical signs observed. Animals became highly apprehensive and over-reactive, squealing loudly and fleeing in apparent panic whenever approached or touched. Subsequent behavioral changes suggested confusion in all pigs and depression in 5, which showed listlessness. P-6 showed apparent confusion and anxiety that increased with the progression of the disease. Behavioral changes were accompanied by initially mild hind-limb ataxia followed by progressive locomotor disability with generalized ataxia of gait, weakness and other movement disorders in all pigs. Pigs showed low carriage of the head and ears and signs of tremor in the shoulder regions, flanks and the ears. Persistent recumbency with difficulty rising was also observed.

Table 1 Clinical and pathological features.

\begin{tabular}{|c|c|c|c|c|c|c|}
\hline Animal id. & $\begin{array}{l}\text { Incubation } \\
\text { period (weeks) }\end{array}$ & $\begin{array}{l}\text { Euthanasia } \\
\text { date (weeks) }\end{array}$ & Clinical Signs & NPC & $\operatorname{PrP} \mathrm{P}^{\mathrm{Sc}}$ & PrPres \\
\hline$P-1$ & 96 & 116 & Present-Dull form & Present & Present & Present \\
\hline$P-2$ & 109 & 132 & Present-Dull form & Present & Present & Present \\
\hline$P-3$ & 96 & 115 & Present-Dull form & Present & Present & Present \\
\hline$P-4$ & 109 & 131 & Present-Dull form & Present & Present & Present \\
\hline$P-5$ & 77 & 90 & Present-Dull form & Present & Present & Present \\
\hline P-6 & 109 & 131 & Present-Aggressiveness & Present & Present & Present \\
\hline P-7 & & 42 & Absent & Absent & Absent & Absent \\
\hline P-8 & & & & Absent & Absent & Absent \\
\hline
\end{tabular}

Animal identification number, incubation period, euthanasia date, clinical signs, neuropathological changes (NPC) as determined by hematoxylin-eosin (HE) staining, presence of $\mathrm{PrP}^{\mathrm{SC}}$ (immunohistochemistry) and presence of $\mathrm{PrP}^{\text {res }}$ in CNS samples (Western blot). 


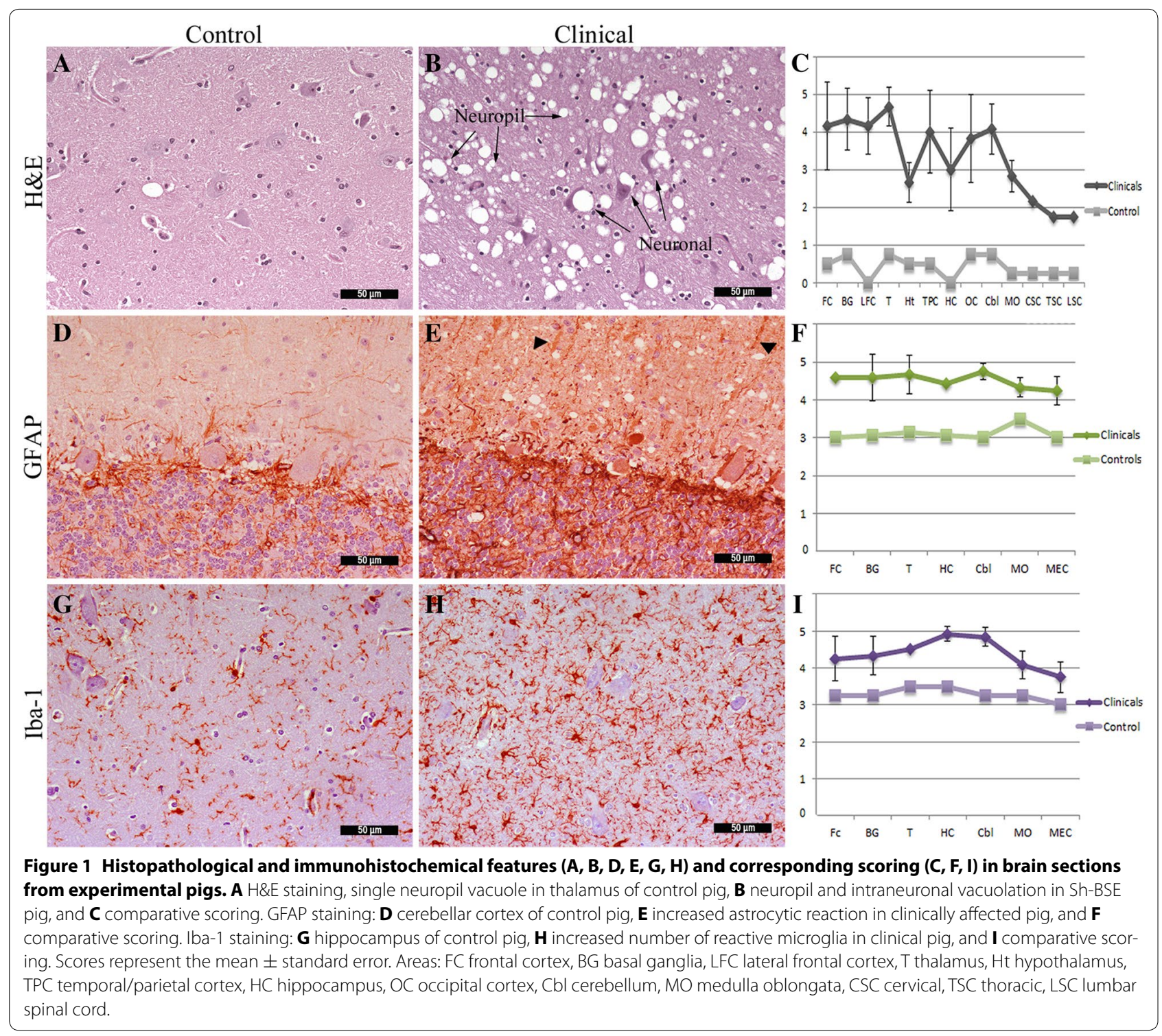

\section{Histopathology and immunohistochemistry of the CNS}

Microscopic evaluation revealed occasional neuropil vacuolation in the molecular layer of the cerebral and cerebellar cortex, thalamus/hypothalamus (Figure 1A) and white matter of different brain sections of the control and preclinical disease stage pigs. Unlike in other species, the incidental vacuolation in the pig cannot be unequivocally differentiated from TSE specific vacuoles, a lesion profile from the negative control is also presented for comparison. Large intraneuronal and neuropil vacuolation (spongiform changes) and increased glial cell reaction were observed only in the CNS of pigs that developed neurological signs.

Five of the 6 clinically affected pigs showed severe neuropil and neuronal vacuolation in the cerebral cortex.
This effect was milder in P-2. Lesions were more severe in frontal versus occipital areas and were severe in deeper layers of the cerebral cortex. In the basal ganglia, severe neuropil vacuolation was observed in the caudate nucleus in all clinical animals. Neuronal vacuolation in the septum was moderate in 5 pigs and mild in one case (P-1). In hippocampal regions CA1 and CA3 neuronal vacuolation was severe in P-1 and P-3, and mild in the remaining 4 pigs. Occasional neuropil vacuolation of the gyrus dentatus was observed in P-1 and P-3.

Lesions decreased in intensity in a rostro-caudal direction in the brain stem. All pigs showed extreme vacuolation in the thalamus (Figure 1B) and relatively mild vacuolation in the hypothalamus. Moderate-to-severe neuropil vacuolation and a mild-to-moderate neuronal 
vacuolation were observed in the mesencephalon of $\mathrm{P}-2$, P-4 and P-6, particularly in the red nuclei, trigeminal and facial medullary nuclei. Occasional mild spongiosis was detected in the oculomotor nuclei. In the medulla oblongata, mild-to-moderate spongiosis was observed in the HMN, RF and ON and moderate-to-severe spongiosis in the DMNV and NTN. Occasional neuronal vacuoles were observed in the HMN, NTN, ON and RF and mild vacuolation in the DMNV. In all pigs the dorsal and ventral horns of the spinal cord exhibited occasional neuronal and neuropil vacuolation. All lobes of the cerebellar cortex showed severe vacuolation, especially the molecular and granule-cell layers. Histopathological differences between control and affected animals are shown in Figure $1 C$.

GFAP immunostaining in the control pig (P-8) revealed non-reactive astrocytes, mainly in white matter, mild staining of fine fibers in the grey matter, and moderate ependymal and perivascular staining in all sections. In the HC, GFAP staining was observed in the molecular layer adjacent to the granular cell layer in the fascia dentata. Occasional-to-mild staining in the granular and molecular layers was also seen in the control cerebellum (Figure 1D). P-8 showed a mild increase in GFAP staining. A widespread and marked increase in GFAP expression was observed in the brains of clinically-affected pigs. This increase was due to the greater abundance of large size astrocytes in the gray and white matter, mainly in the FC, BG, T and Cbl. Immunolabelling was also observed in the prolongations of Bergmann glia of the molecular layer of the cerebellum (Figure 1E). Differences in the distribution of GFAP staining between control and Sh-BSE brain sections are shown in Figure 1F.

Microglia was analyzed by specific Iba-1 IHC, which revealed immunolabelling in the white matter in various sections of the negative control pig (Figure 1G). An abundance of microglia with much larger round or amoeboid cell bodies was observed in the brain sections of clinically affected pigs (Figure $1 \mathrm{H}$ ). The increase in Iba-1 expression was particularly marked in the $\mathrm{T}, \mathrm{HC}$ and $\mathrm{Cbl}$, and less immunolabeling in the spinal cord (Figure 1I).

IHC revealed no PrP ${ }^{\mathrm{Sc}}$ deposition in the CNS of the control and preclinical animals. Nine different deposition types were clearly identified in the CNS of the clinically affected pigs and confirmed the diagnosis of a TSE in these animals. The $\operatorname{PrP}^{\mathrm{Sc}}$ types found were as follows:

Intraneuronal type (ITNR): accumulation of fine to coarse granular deposits of $\mathrm{PrP}^{\mathrm{Sc}}$ in the neuronal perikarya surrounding the nucleus (Figure 2A). This pattern was especially observed in different sections of the spinal cord, DMNV, NTN and ON nuclei in medulla oblongata, thalamus and hippocampus.
Intra-astrocytic type (ITAS): this type was expressed by multiple small granules scattered in the cytoplasm of astrocyte-resembling cells.

Intra-microglial type (ITMG): characterized by one as single or a few large granules in close proximity to microglia-like nuclei.

Both ITAS and ITMG were found in all the sections, especially in thalamus and hippocampus, but well identified in the white matter of cerebral (Figure 2B) and cerebellar cortex, although in less amounts than in the grey matter.

Perineuronal type (PNER): thin deposits of $\operatorname{PrP}^{\mathrm{Sc}}$ around the plasmalemma of the neuronal bodies observed in moderated levels in different basal ganglia nuclei (Figure 2C).

Linear type (LINR): thick thread-like deposits of $\mathrm{PrP}^{\mathrm{Sc}}$ in the neuropil occasionally present in the basal ganglia (Figure 2C) and hippocampus associated to PRCO type.

Perivascular type (PRVS): thick, strongly labeled $\operatorname{PrP}^{\mathrm{Sc}}$ accumulation around blood vessels located in the gray matter of the cerebral cortices (Figure 2D).

Perivaculoar type (PRVC): $\operatorname{PrP}^{\mathrm{Sc}}$ deposits surrounding vacuolar lesions were detected in cerebral (Figure 2D) and cerebellar cortex, basal ganglia and thalamus in all the pigs.

Subpial type (SBPL): continuous loose mesh of $\operatorname{PrP}^{\mathrm{Sc}}$ accumulation underneath the pia mater, especially in the cerebral (Figure 2E) and cerebellar cortex.

Particulate to coalescing type (PRCO): Conspicuous deposits in the neuropil associated with amorphous masses of $\mathrm{PrP}^{\mathrm{Sc}}$ were observed in the gray matter of the cerebral cortex (Figure 2F), it was diffuse in 5 pigs and multifocal in P-4. This pattern was also observed in the cerebellar cortex, basal ganglia, thalamus/hypothalamus and hippocampus. Fine particles were observed in the septal and caudate nuclei in basal ganglia.

The predominant $\mathrm{PrP}^{\mathrm{Sc}}$ types present in the CNS of all the pigs were the ITNR and the PRCO, while the LINR type was the less observed (Figure $2 \mathrm{G}$ ).

The $\mathrm{PrP}^{\mathrm{Sc}}$ distribution pattern along the different sections of the CNS revealed that the higher deposits were observed in the cerebral cortex; thalamus and cerebellum, whilst the lowest depositions were in the hypothalamus and spinal cord (Figure $2 \mathrm{H}$ ).

The global Spearman correlation values for histopathology and immunohistochemistry in all samples are shown in Table 2 . Spongiform changes were significantly correlated $(P<0.001)$ with $\operatorname{PrP}^{\mathrm{Sc}}$ deposition. Despite no correlation between spongiform changes and glial reactivity, $\mathrm{PrP}^{\mathrm{Sc}}$ deposition was significantly correlated with GFAP and Iba-1 immunostaining. Moreover, a significant correlation was observed between GFAP and Iba-1 immunostaining $(P<0.001)$. 


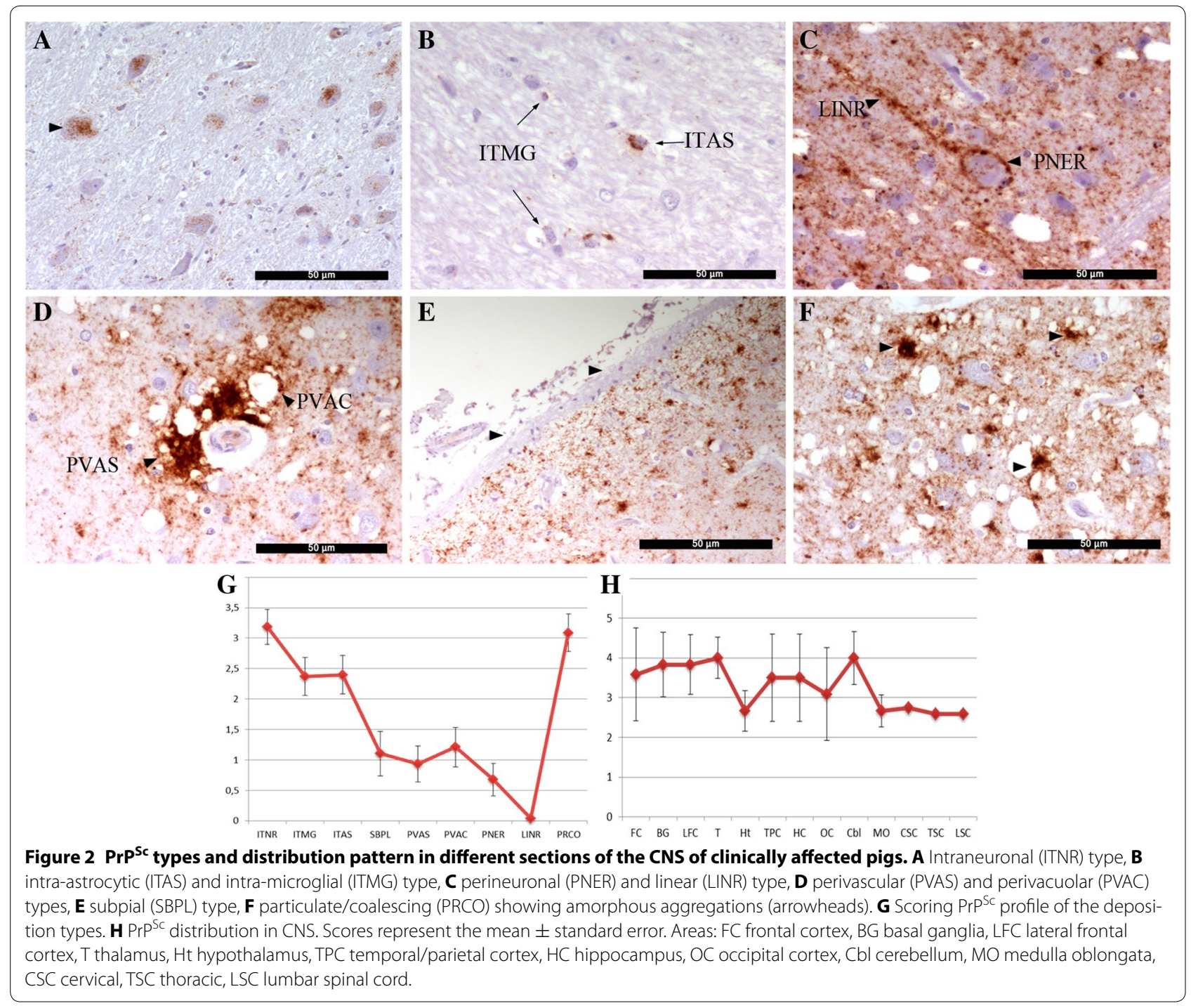

Table 2 Spearman correlation values between histological features (vacuolation and PrPSc; GFAP and Iba-1) in all groups.

\begin{tabular}{llll}
\hline Spearman's rho & PrP $^{\text {Sc }}$ & GFAP & lba-1 \\
\hline Vacuolation & $856(* * *)$ & & \\
PrPSc & & $3311^{(* *)}$ & $316\left({ }^{* *}\right)$ \\
GFAP & & & $912(* * *)$ \\
\hline
\end{tabular}

Correlations were estimated using the full set of data obtained from all CNS sections (global correlation)

Empty cells No correlation or duplicated results

** Correlation is very significant at the 0.01 level

*** Correlation is highly significant at the 0.001 level

\section{Histopathology and $\mathrm{PrP}^{\mathrm{Sc}}$ detection in the retina}

The control pig showed no histopathological changes in the optic nerve or retina (Figure 3A). However, clinically affected pigs showed histological lesions of the retina of varying degrees of severity. Histopathological findings included loss of outer limiting layer definition, outer plexiform layer (OPL) atrophy, and disorganization and loss of nuclei of both outer (ONL) and inner nuclear layers (INL). A thickening of the photoreceptor layer (PS) was also observed, a result of the disorganization and elongation of the photoreceptor segments (Figure 3B). While no $\operatorname{PrP}^{\mathrm{Sc}}$ was detected in the optic nerve or retina (Figure $3 \mathrm{C}$ ) of the control pig, occasional granular $\operatorname{PrP}^{\mathrm{Sc}}$ deposition was observed in the optic nerve of five clinically affected pigs. $\operatorname{PrP}^{\mathrm{Sc}}$ was also observed in the neuroretina of all clinically affected pigs in the ganglion cell layer, OPL and IPL. The deposition pattern was granular in the plexiform layers of the retina and intraneuronal in the ganglion cell layer (Figure 3D). $\operatorname{PrP}^{\mathrm{Sc}}$ was not detected in any ocular tissues other than the neuroretina. 


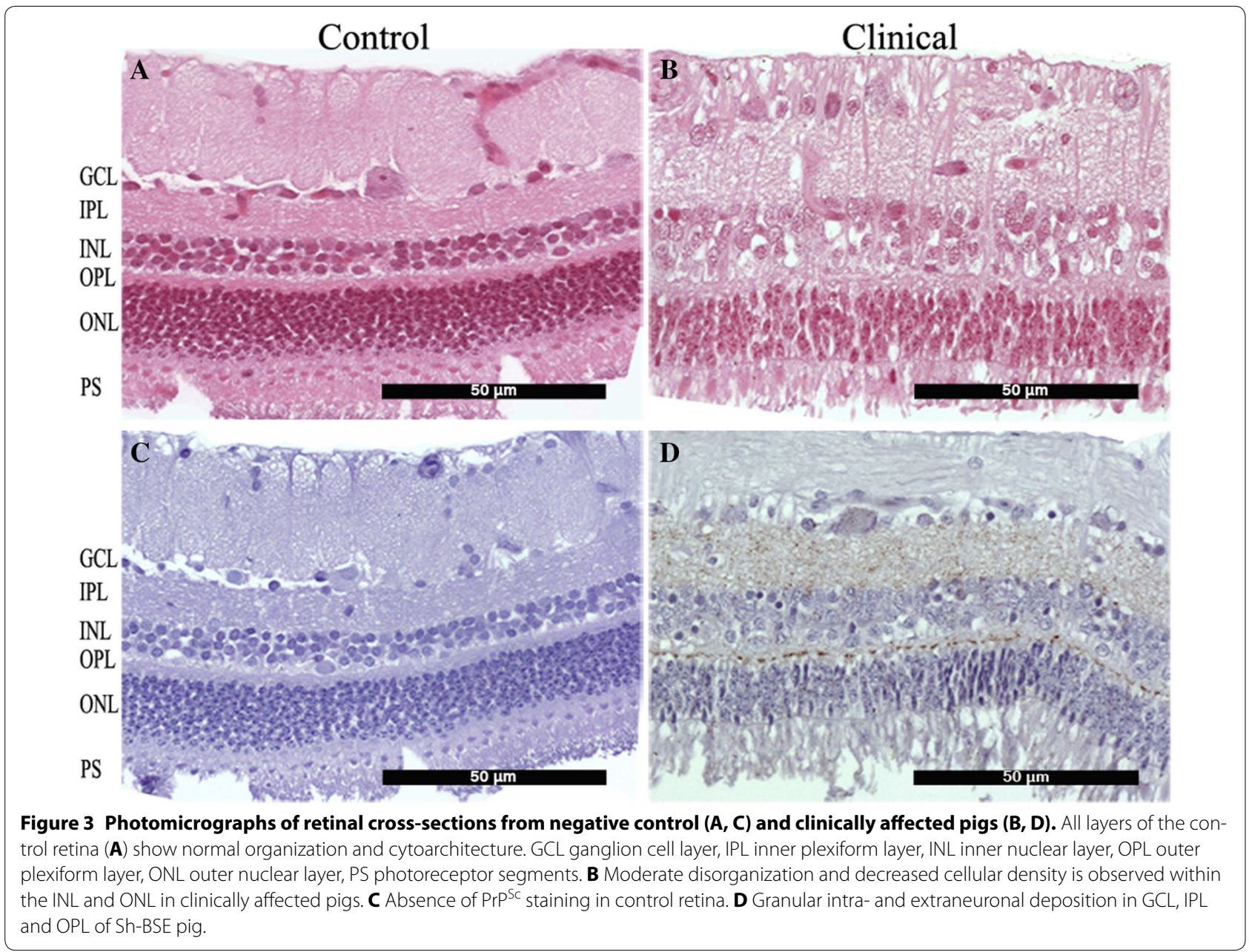

\section{Western blot analysis}

Western blot revealed no $\mathrm{PrP}^{\mathrm{res}}$ in the CNS of preclinical (P-7) and control (P-8) pigs. However, brain sections from clinically affected pigs showed a characteristic 3-band pattern. The medulla oblongata band signal appeared to be less intense than the frontal cortex, thalamus and cerebellum samples (Figure 4A). Differences in the molecular signature between the original inoculum (Sh-BSE) and sheep-BSE in pigs were observed. The molecular mass of the diglycosylated band of Sh-BSE was higher than that of porcine Sh-BSE, which produced a predominant monoglycosylated band. By contrast, the molecular masses of the unglycosylated $\mathrm{PrP}^{\text {res }}$ were similar (Figure 4B).

\section{Immunoassay analysis}

The results of IDEXX revealed optical density (OD) values of 0.03 in the negative control and 3.695-4.349 in the CNS of clinically affected pigs (Table 3 ).
Histopathology, immunohistochemistry and immunoassay of the peripheral tissues

No histopathological changes were observed outside the CNS of clinically affected pigs. However, IHC and/or IDEXX revealed widespread $\mathrm{PrP}^{\mathrm{Sc}}$ distribution in organs outside the CNS of these animals. Individual results of the $\operatorname{Pr} \mathrm{P}^{\mathrm{Sc}}$ detection assay are provided in Table 3 .

\section{$\mathrm{PrP}^{\mathrm{Sc}}$ detection in the peripheral nervous system (PNS)}

The vagus nerve resulted positive by the $\operatorname{PrP}^{\mathrm{Sc}}$ detected in the DMNV in the MO by IHC. Both IHC and IDEXX revealed $\mathrm{PrP}^{\mathrm{Sc}}$ in the brachial nerve of $\mathrm{P}-2$ and $\mathrm{P}-3$ with OD values ranging from 0.173 to 0.208 and in the sciatic nerve in all pigs, with OD values ranging from 0.160 to 0.430. Transversal sections of peripheral nerves showed small amounts of periaxonal labeling in some nerve fibers (Figure 5A). No neural $\operatorname{PrP}^{\mathrm{Sc}}$ was detected in the control pig (Figure 5B). 


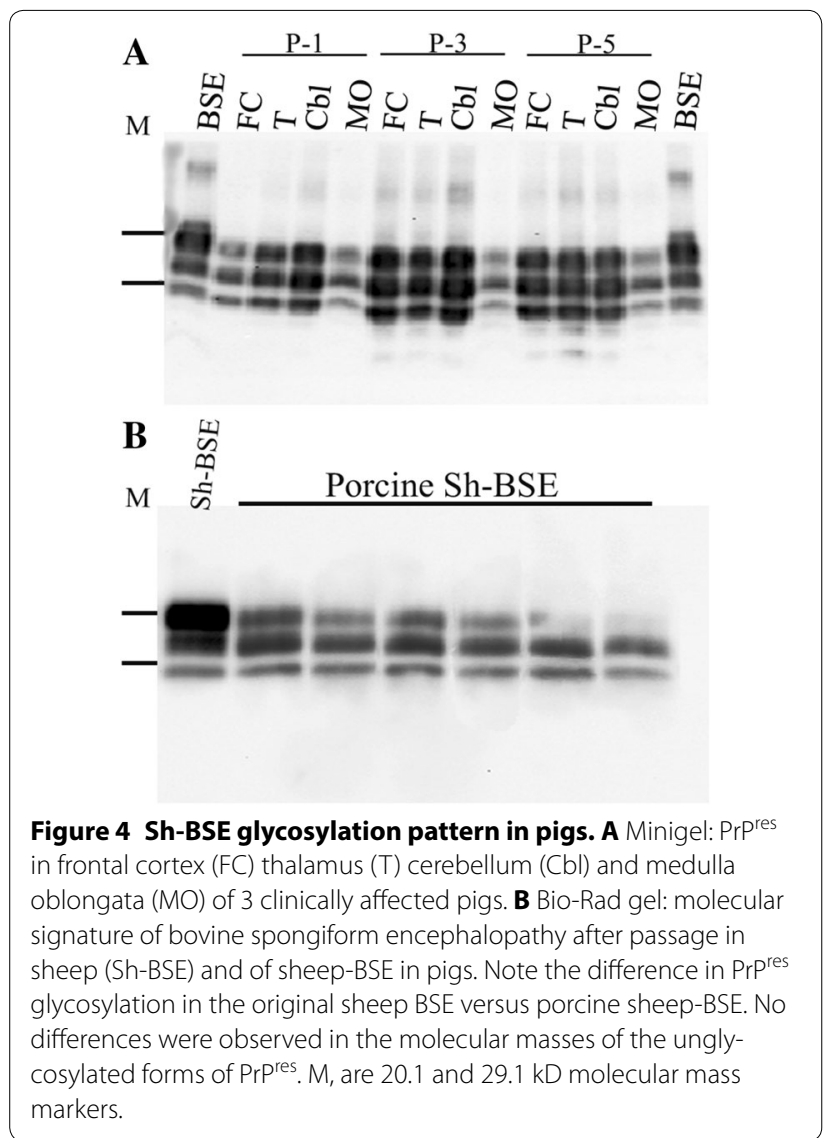

\section{$\mathrm{PrP}^{\mathrm{SC}}$ detection in the lymphoreticular system (LRS)}

In $\mathrm{P} 1$ and $\mathrm{P} 4, \mathrm{PrP}^{\mathrm{Sc}}$ was detected in the palatine tonsil in the form of granules in tingible body macrophages (TBM) present in the lymphoid follicles (Figure 5C). This pattern was also observed in the submandibular lymph node in $\mathrm{P}-2$, the mediastinal lymph node in $\mathrm{P}-1$, and the mesenteric lymph node in P-2, P-4 and P-5, with OD values ranging from 0.152 to 0.545 (IDEXX). Neither IHC nor IDEXX detected $\mathrm{PrP}^{\mathrm{Sc}}$ in the spleen of clinically affected or control pigs. Gut associated lymphoid tissues (GALT) were also negative in all cases. No $\mathrm{PrP}^{\mathrm{Sc}}$ was observed in the lymphoid tissues of the control pig (Figure 5D).

\section{$\mathrm{PrP}^{\mathrm{Sc}}$ detection in the gastrointestinal tract (GIT)}

$\mathrm{PrP}^{\mathrm{Sc}}$ deposits were consistently detected in the enteric nervous system, with granular intracytoplasmic accumulation observed in neurons of the myenteric (Auerbach's) plexus (Figure 5E). Positivity was detected in the stomach, duodenum, jejunum, ileum, caecum, colon and rectum, with levels varying between animals. P-1, which was euthanized at $116 \mathrm{wpi}$, showed more positive sections than P-2, P-4 or P-6, which had longer incubation periods. Positive staining was also detected in the duodenum and jejunum in three and four pigs, respectively, and in the caecum, colon and rectum in one of the six pigs. Both methods revealed positive staining in the distal ileum in all pigs. This finding suggests that the ileum is the first part of the GIT to be reached by prions. No $\operatorname{PrP}^{\mathrm{Sc}}$ accumulation was observed in the negative control or preclinical pigs (Figure 5F).

\section{PrPSc detection in skeletal muscle}

Both assay methods detected $\operatorname{PrP}^{\mathrm{Sc}}$ in skeletal muscle samples from oculomotor muscle in P-1 and P-4. IHC revealed granular $\operatorname{PrP}^{\mathrm{Sc}}$ deposit restricted to the muscle spindles (Figure 5G); $\operatorname{PrP}^{S c}$ immunolabeling was not detected in myofibrils, intramuscular nerve fascicles or in most ganglia in the muscle samples analyzed. $\mathrm{PrP}^{\mathrm{Sc}}$ was detected in oculomotor muscle and semitendinosus muscle in P-5 by IDEXX only. No $\mathrm{PrP}^{\mathrm{Sc}}$ accumulation was detected by either method in muscle samples from control and preclinical pigs (Figure $5 \mathrm{H}$ ).

\section{$\mathrm{PrP}^{\mathrm{Sc}}$ detection in the pancreas}

$\mathrm{PrP}^{\mathrm{Sc}}$ was detected in the pancreas of five clinically affected pigs by $\mathrm{IHC}$ only. $\mathrm{PrP}^{\mathrm{Sc}}$ deposition was observed in structures of the PNS. In these samples, intracytoplasmic and perineuronal immunolabeling was observed in the parasympathetic postganglionic neurons in pancreatic tissue (Figure $6 \mathrm{~A}$ ). No $\mathrm{PrP}^{\mathrm{Sc}}$ was detected in $\mathrm{P}-2$ or in the control pig (Figure 6B). No pancreatic $\operatorname{PrP}^{\mathrm{Sc}}$ was detected in any of the pigs analyzed using the IDEXX technique.

\section{PrP ${ }^{\mathrm{Sc}}$ detection in the adrenal gland}

$\mathrm{PrP}^{\mathrm{Sc}}$ was detected in the medullar region of the adrenal gland of P-2 in the form of granular intracytoplasmic deposits in ganglionic neurons and chromaffin cells (Figure 6C). IDEXX revealed an OD value of 0.150 . However, IHC revealed no clear positivity for $\operatorname{PrP}^{\mathrm{Sc}}$ in $\mathrm{P}-5$, for which IDEXX determined an OD of 0.191. No $\operatorname{PrP}^{\mathrm{Sc}}$ was detected in the adrenal gland of any other clinically affected or control pigs (Figure 6D).

\section{PrPSc detection in the kidney}

Granular $\operatorname{PrP}^{\mathrm{Sc}}$ deposition was observed exclusively within the epithelial tubular cells of the convoluted tubes and collecting ducts in P-1 (Figure 6E). This result was not consistent with the IDEXX result, which was negative. The kidneys of the remaining clinically affected and control pigs were negative in both assays (Figure 6F).

\section{Discussion}

This study was aimed at investigating the susceptibility and neuropathological features of pigs intracerebrally inoculated with the BSE agent after passage in sheep, as 
Table 3 PrP $^{S C}$ detection by immunohistochemistry (IHC) and IDEXX in the central nervous system (CNS), peripheral nervous system (PNS), lympho-reticular (LRS), gastrointestinal tract (GIT), skeletal muscles (SM) and other organs of individual pigs.

\begin{tabular}{|c|c|c|c|c|c|c|c|c|c|c|c|c|c|c|c|}
\hline \multirow[t]{2}{*}{ SITE } & \multirow[t]{2}{*}{ Tissue } & \multicolumn{2}{|l|}{ P1 } & \multicolumn{2}{|l|}{ P2 } & \multicolumn{2}{|l|}{ P3 } & \multicolumn{2}{|l|}{ P4 } & \multicolumn{2}{|l|}{ P5 } & \multicolumn{2}{|l|}{ P6 } & \multicolumn{2}{|l|}{ P8 } \\
\hline & & $\mathrm{IHC}$ & EIA & IHC & EIA & $\mathrm{IHC}$ & EIA & IHC & EIA & IHC & EIA & IHC & EIA & $\mathrm{IHC}$ & EIA \\
\hline \multirow[t]{3}{*}{ CNS } & Brain & + & 4.22 & + & 3.93 & + & 3.69 & + & 3.75 & + & 3.90 & + & 4.34 & - & 0.03 \\
\hline & Retina & + & ND & + & ND & + & ND & + & ND & + & ND & + & ND & - & ND \\
\hline & Optic nerve & + & ND & + & ND & + & ND & + & ND & + & ND & + & ND & - & ND \\
\hline \multirow[t]{3}{*}{ PNS } & Vagus nerve & + & ND & + & ND & + & ND & + & ND & + & ND & + & ND & - & - \\
\hline & Brachial nerve & - & - & + & 0.20 & + & 0.17 & - & - & - & - & - & - & - & - \\
\hline & Sciatic nerve & + & 0.43 & + & 0.30 & + & 0.28 & + & 0.29 & + & 0.34 & + & 0.16 & - & - \\
\hline \multirow[t]{8}{*}{ LRS } & Tonsil & + & 0.17 & + & 0.08 & - & - & + & 0.15 & - & - & - & - & - & - \\
\hline & Retropharyngeal In. & - & - & - & - & - & - & - & - & - & - & - & - & - & - \\
\hline & Submandibular In. & - & - & - & 0.35 & - & - & - & - & - & - & - & - & - & - \\
\hline & Prescapular In. & - & - & - & - & - & - & - & - & - & - & - & - & - & - \\
\hline & Mediastinal In. & + & 0.16 & - & - & - & - & - & - & - & - & - & - & - & - \\
\hline & Spleen & - & - & - & - & - & - & - & - & - & - & - & - & - & - \\
\hline & Mesenterial In. & - & - & + & 0.23 & - & - & + & 0.19 & + & 0.54 & - & - & - & - \\
\hline & Popliteal In. & - & - & - & - & - & - & - & - & - & - & - & - & - & - \\
\hline \multirow[t]{8}{*}{ GIT } & Oesophagus & - & - & - & - & - & - & - & - & - & - & - & - & - & - \\
\hline & Stomach & + & - & - & - & - & - & - & - & - & - & + & - & - & - \\
\hline & Duodenum & ++ & - & - & - & - & - & ++ & - & - & - & + & - & - & - \\
\hline & Jejunum & ++ & 0.24 & - & - & + & - & ++ & - & - & - & + & - & - & - \\
\hline & Ileum & +++ & 0.40 & +++ & 0.72 & ++ & 0.22 & +++ & 1.48 & + & 0.23 & ++ & 0.31 & - & - \\
\hline & Caecum & + & - & - & - & - & - & - & - & - & - & - & - & - & - \\
\hline & Colon & + & - & - & - & - & - & - & - & - & - & - & - & - & - \\
\hline & Rectum & + & - & - & - & - & - & - & - & - & - & - & - & - & - \\
\hline \multirow[t]{3}{*}{ SM } & Oculomotor & + & 1.00 & - & - & - & - & + & 2.83 & - & 0.67 & - & - & - & - \\
\hline & Brachial biceps & - & - & - & - & - & - & - & - & - & - & - & - & - & - \\
\hline & Semitendinosus & - & - & - & - & - & - & - & - & - & 0.20 & - & - & - & - \\
\hline \multirow[t]{10}{*}{ Other } & Tongue & - & - & - & - & - & - & - & - & - & - & - & - & - & - \\
\hline & Olfactory mucosa & - & - & - & - & - & - & - & - & - & - & - & - & - & - \\
\hline & Heart & - & - & - & - & - & - & - & - & - & - & - & - & - & - \\
\hline & Lung & - & - & - & - & - & - & - & - & - & - & - & - & - & - \\
\hline & Liver & - & - & - & - & - & - & - & - & - & - & - & - & - & - \\
\hline & Adrenal gland & - & - & - & - & + & 0.15 & - & - & + & 0.19 & - & - & - & - \\
\hline & Urinary bladder & - & - & - & - & - & - & - & - & - & - & - & - & - & - \\
\hline & Kidney & + & - & - & - & - & - & - & - & - & - & - & - & - & - \\
\hline & Pancreas & + & - & - & - & + & - & + & 0.21 & + & - & + & - & - & - \\
\hline & Uterus & - & - & - & - & - & - & - & - & - & - & - & - & - & - \\
\hline
\end{tabular}

well as describing the $\operatorname{PrP}^{\mathrm{Sc}}$ distribution in peripheral tissues in this species.

In the present study, seven pigs were intracerebrally inoculated with $0.5 \mathrm{~mL}$ of $10 \%$ Sh-BSE homogenate. Except in one animal (P-7), which was euthanized for preclinical analysis, the transmission rate was $100 \%$, with an incubation period range of 77-109 wpi. Two previous studies in which bovine BSE has been transmitted to pigs, reported $87.5 \%$ and $20 \%$ of rate attacks, with incubation period ranges of 74-163 and 148-175 wpi, respectively $[19,20]$. Sh-BSE infected pigs show slightly shorter incubation periods. However, it is not possible to compare the incubation period of our inoculated pigs with respect to the incubation period found in the studies mentioned above, due to the lack of titration of the original inoculum. Moreover, the incubation period could also be modified in TSE due to the species barrier, which is modulated by specific polymorphisms of the PRNP gene and 


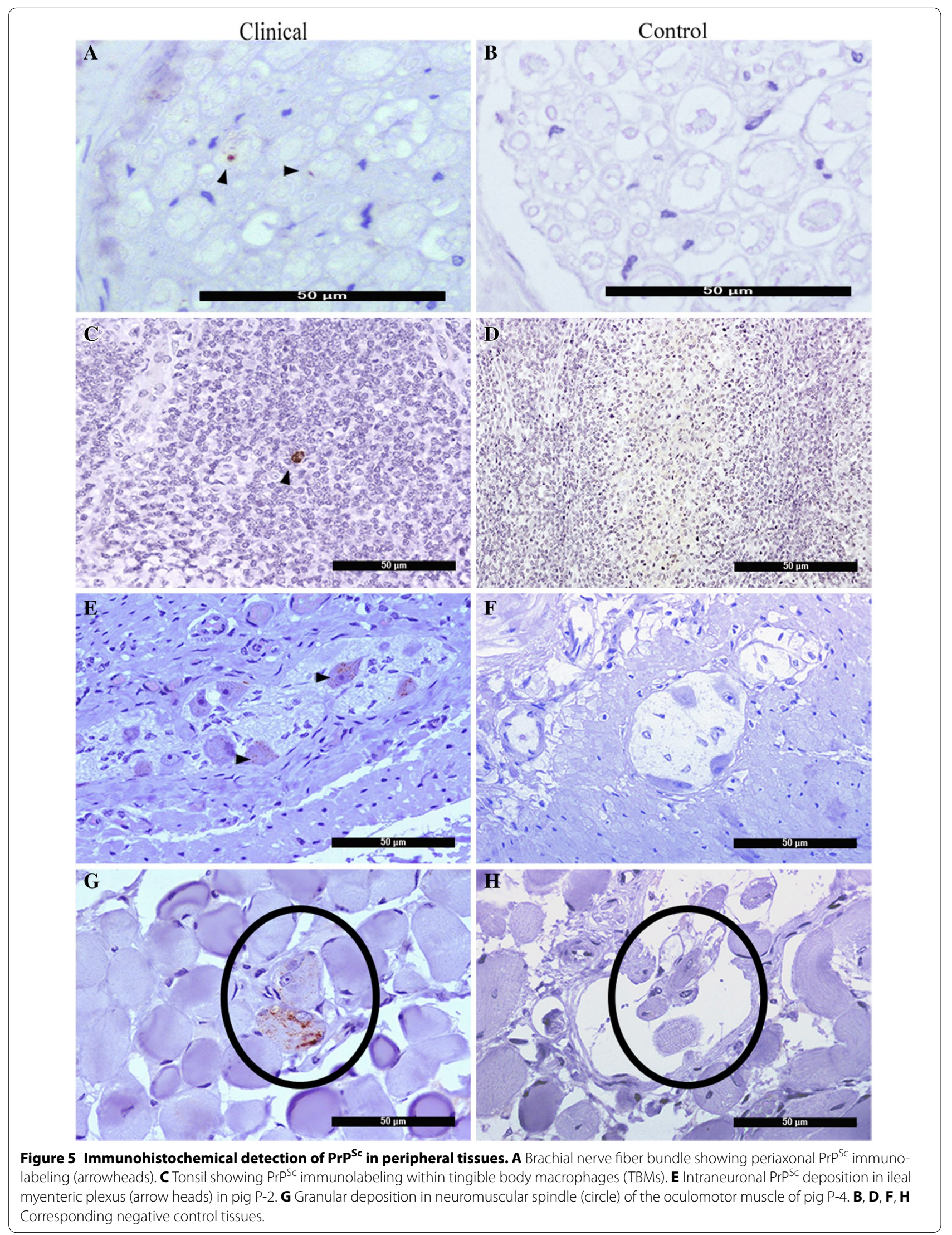




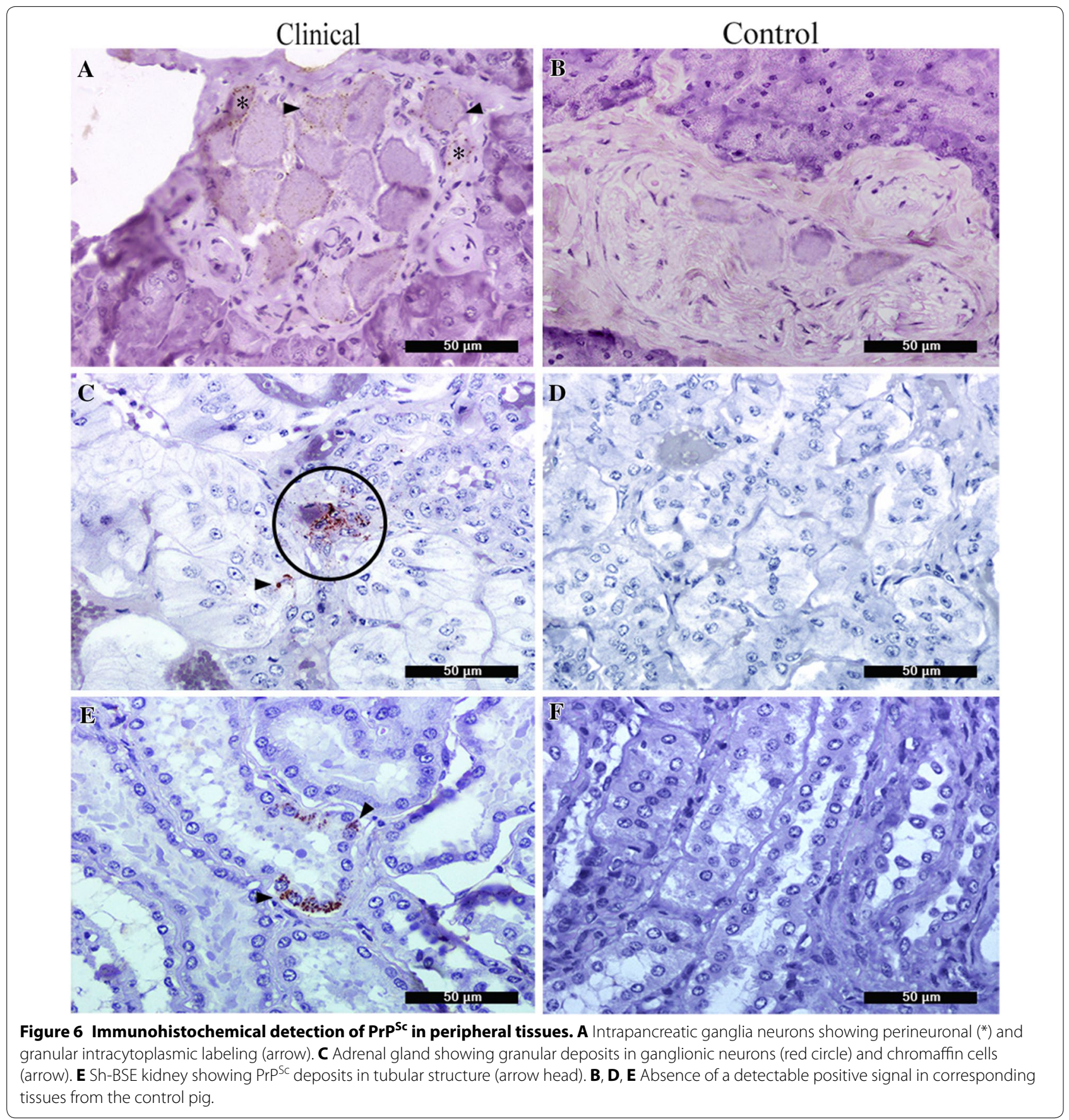

plays a key role in susceptibility to prion disease in other species such as sheep [35, 36], and goats [37]. Although some studies show that there are no differences in the sequence of the porcine PRNP gene [38-40], the possibility of changes in other regions of the gene or the involvement of other genes in the incubation periods of BSE in pigs should not be excluded. In addition, the restricted number of animals used does not allow comparing difference on rate attacks in previous studies with the present report. However, transmissible studies in porcine PRNP transgenic mice (Tgpo) has demonstrated that the Sh-BSE agent reached rate attack of $100 \%$ and lower survival time when compared to the original bovine BSE (19\%) and other BSE isolates at first passage [15]. At two subsequent passages, the transmission rate of both ShBSE and bovine BSE was reported to be similar (100\%) 
but always with a lower survival time of the Sh-BSE infected mice [15]. Recent studies have demonstrated an increase in the PrP-converting potency of Sh-BSE caused by decreases in polymorphism barriers [24] and other specific cellular factors [25], allowing Sh-BSE to be transmitted more efficiently than cattle BSE to other species $[16,17]$ including supposedly less susceptible hosts such as pigs [15]. The current study was in agreement with previous reports [20-22] involving intracerebral inoculation of BSE prions to pigs demonstrating that this species is susceptible to BSE. However, it is still unknown if pigs can succumb to BSE after oral exposure which is the most likely route of inoculation under natural conditions.

The clinical signs observed in the present study were similar to those described in BSE-infected pigs [20]. Animals initially showed progressive confusion, followed by motor deficits [19]. The behavioral and sensory changes were also consistent with those observed in cattle infected naturally [41] and experimentally with BSE [12]. The minimal neuropil vacuoles found in the control pig are in total agreement with previous studies [21] and apparently does not represent a clinical significant change [20]. The main pathological changes observed were neuropil spongiosis, intraneuronal vacuolation and $\mathrm{PrP}^{\mathrm{Sc}}$ deposition, all of which are characteristic of TSE [41]. The lesion distribution pattern resembled that described previously in experimentally BSE- infected pigs [21] and cattle [12]; the thalamus was the most affected area, followed by the cerebellar and cerebral cortices, with the mildest effect observed in the spinal cord. $\mathrm{PrP}^{\mathrm{Sc}}$ deposits were identified in the CNS of all clinically affected pigs. $\mathrm{PrP}^{\mathrm{Sc}}$ deposits were typically associated with lesions in the fourth and fifth layers of the cerebral cortex. Intracellular (ITNR, ITAS and ITMG) and particulate/coalescing type $\operatorname{PrP}^{\mathrm{Sc}}$ deposition were the most commonly observed patterns in the different CNS samples, in line with previous findings in sheep $[29,30]$ and pigs [21] experimentally infected with BSE. Similarities in the $\mathrm{PrP}^{\mathrm{Sc}}$ deposition types and distribution pattern could be explained by the high stability of the BSE agent reported for different breeds and different genotypes of the prion protein gene (PRNP) in sheep [30]. In addition, the porcine PRNP gene has been described to be very homogenous [38-40].

The glial reaction in all affected pigs was characterized by marked astrocytosis and microgliosis. Astrocytosis was diffusely distributed throughout the brain of affected pigs, perhaps caused by the accumulation of $\mathrm{PrP}^{\mathrm{Sc}}$ or by cytokines secreted from astroglial or microglial cells [42]. Microgliosis was present in the deeper layers of the gray matter in the cerebral cortex, which also showed vacuolation and $\mathrm{PrP}^{\mathrm{Sc}}$ deposition, in accordance with previous findings in mice [43]. The most extreme microglial activation was observed in the hippocampus of all affected pigs, as previously described for CJD [44]. Numerous astrocytic processes and reactive microglia have been described in pigs experimentally infected with BSE [45]. Our results suggest that astrogliosis and microgliosis are common neuropathological features of Sh-BSE infection in pigs, as described for TSE in other species [28, 43, 45-47].

Histopathological changes indicative of retinal degeneration were observed in all clinically affected pigs. This has not been previously described in pigs experimentally infected with BSE. Neuronal vacuolation in the GCL and disorganization in the plexiform and nuclear layers have been reported in both experimental [48] and natural scrapie infections in sheep [49] and goats [50], chronic wasting disease (CWD) in mule deer [51] and in CJDinfected mice [52]. IHC revealed higher levels of $\operatorname{PrP}^{\mathrm{Sc}}$ in the retina than in the optic nerve, where staining was less intense and more irregularly distributed, as described in both SCJD and nvCJD [53]. The presence of $\operatorname{PrP}^{\mathrm{Sc}}$ in the optic nerve and retina is consistent with the centrifugal spread of the agent from the brain, presumably via the optic nerve [52]. This may indicate the existence of other routes of $\mathrm{PrP}^{\mathrm{Sc}}$ migration to the retina (e.g., via the extracellular space [54], the ad-axonal route along the optic nerve, or both [55]). Other authors have suggested that the spread occurs from the subarachnoid space into the perineural space of the optic nerve, and from there to the epichoroidal and episcleral tissues of the eyeball [56]. Alternatively, the increased presence of $\mathrm{PrP}^{\mathrm{Sc}}$ in the retina more than in the optic nerve could be attributed to the higher presence of $\operatorname{PrP}^{\mathrm{c}}$ in the membranes of retinal neurons. Our detection of $\mathrm{PrP}^{\mathrm{Sc}}$ in different retinal layers is in accordance with previous observations in TSE in mice [52], feline spongiform encephalopathy (FSE) [57], scrapie [49], CWD [51], BSE [56] and in patients with sporadic and nvCJD [53].

Western blot revealed a characteristic 3-band pattern that clearly differed from the original inoculum, with a predominant monoclycosylated band. This finding is consistent with previous Western blot findings in BSEinfected pigs [58]. Our results reinforce the hypothesis that this particular signature is associated with the porcine $\operatorname{PrP}^{\mathrm{c}}$ properties described in Tgpo mice [15].

The IDEXX enzyme immunoassay, which is not validated for $\operatorname{PrP}^{\mathrm{sc}}$ in pigs, detected $\mathrm{PrP}^{\mathrm{Sc}}$ in samples that tested positive in other postmortem assays, but detected no $\mathrm{PrP}^{\mathrm{sc}}$ in negative control tissues. Analysis of peripheral tissues revealed widespread dissemination of $\mathrm{PrP}^{\mathrm{Sc}}$ in many organs other than the CNS. This finding suggests that unlike in cattle where BSE is confined mainly in the nervous system, in the pig, BSE prions can propagate in peripheral tissues as reported in sheep [59-61]. However, 
it is not possible to ascertain that the peripheral distribution of the agent is due to centrifugal dissemination from the brain through the nerves as it is also probable that during an ic challenge part of the inoculum enters into the blood circulation and can be disseminated to the periphery where it can propagate in target tissues [62].

$\mathrm{PrP}^{\mathrm{Sc}}$ deposition in brachial and sciatic nerves has also been described in cattle experimentally infected with L-type BSE [63] and in BSE-infected sheep [64].

Immunohistochemistry demonstrated the presence of $\mathrm{PrP}^{\mathrm{Sc}}$ in the lymphoreticular system of our Sh-BSE infected pigs. The assay revealed sporadic intracytoplasmic accumulation within the tingible body macrophages in some lymph nodes, findings that were subsequently corroborated by IDEXX, in good agreement with previous findings in sheep experimentally infected with BSE [64]. In contrast to our findings, previous studies reported no infectivity of lymphoid tissues in BSEinfected pigs [19]. No $\operatorname{PrP}^{\mathrm{Sc}}$ was detected in the spleen or GALT of our pigs, in line with previous studies of BSEinfected cattle [65] and FSE [57].

$\mathrm{PrP}^{\mathrm{Sc}}$ accumulation in the gastrointestinal tract of Sh-BSE infected pigs has not been described in similar experiments using this species. We observed $\mathrm{PrP}^{\mathrm{Sc}}$ deposition in the myenteric plexi without apparent morphological alterations of the enteric neurons, as seen in cattle experimentally infected with BSE [65]. This finding is indicative of a potential centrifugal spread of the Sh-BSE agent from the CNS via the vagus nerve to the peripheral nervous system, and may account for the large deposits of $\operatorname{PrP}^{\mathrm{Sc}}$ observed in the dorsal motor nucleus of the vagus nerve in the medulla oblongata.

We observed $\mathrm{PrP}^{\mathrm{Sc}}$ deposition in nerve fibers of the oculomotor muscle in two pigs. In cattle naturally infected with BSE [66], $\mathrm{PrP}^{\mathrm{Sc}}$ has been detected in intramuscular nerve fibers and muscle spindles. Although we found no $\operatorname{PrP}^{\mathrm{Sc}}$ in the oculomotor muscle of any other clinically affected pigs, positive labeling was observed in the oculomotor nuclei in the mesencephalon of all clinically affected pigs.

Pancreatic $\mathrm{PrP}^{\mathrm{Sc}}$ staining was observed in 5 pigs. Analysis of pancreatic nervous tissue has revealed $\mathrm{PrP}^{\mathrm{Sc}}$ deposition in the islets of Langerhans in natural scrapie [34]. In natural BSE [56], $\operatorname{PrP}^{\mathrm{Sc}}$ deposition has been documented in the nerve fibers of the adrenal gland. In agreement with previous findings in natural scrapie [34], one pig showed $\operatorname{PrP}^{\mathrm{Sc}}$ immunolabeling in the medullary region of the adrenal gland, associated with chromaffin cells, which are considered modified sympathetic postganglionic neurons. Similarly, the presence of $\mathrm{PrP}^{\mathrm{Sc}}$ within the epithelial tubular cells of the convoluted tubules and the collecting ducts in the kidney in one pig has been described in FSE [67], suggesting possible prionuria.
In addition to the large amount of $\operatorname{PrP}^{\mathrm{Sc}}$ observed in the CNS of Sh-BSE-infected pigs, $\operatorname{PrP}^{\mathrm{Sc}}$ was widely distributed in the peripheral tissues, although the extent of this distribution varied between animals. This variation may be related to the distribution of $\operatorname{PrP}^{\mathrm{Sc}}$ within individual organs, the exact anatomical location points at which samples were collected, and the detection limits of the techniques used. More sensitive studies, such as in vitro protein misfolding cyclic amplification (PMCA) and mouse bioassays will be needed to clarify the distribution and infectivity of $\operatorname{PrP}^{\mathrm{Sc}}$ in peripheral tissues of Sh-BSE infected pigs. These assays will most likely indicate a higher number of $\mathrm{PrP}^{\mathrm{Sc}}$-positive peripheral organs.

Comparison with previous studies of cattle-BSE in pigs revealed that the incubation period of Sh-BSE in our pigs was generally shorter $[20,21]$ and that $\operatorname{Pr} \mathrm{P}^{\mathrm{Sc}}$ was present in more peripheral tissue types [19]. We believe that these differences may be due to a modification in the pathogenicity of the cattle-BSE agent caused by its prior passage in sheep, as previously described in TgPo mice [15]. However, studies of natural routes of transmission (e.g., oral) will be required to determine the real susceptibility of pigs to the ShBSE agent.

\section{Abbreviations}

BG: basal ganglia; BSE: bovine spongiform encephalopathy; PrPC: cellular prion protein; CNS: central nervous system; Cbl: cerebellum; CSC: cervical spinal cord; CJD: Creutzfeldt-Jakob Disease; DMNV: dorsal motor nucleus of the vagus nerve ${ }_{i}$ FSE: feline spongiform encephalopathy; FC: frontal cortex; GIT: gastrointestinal tract; GFAP: glial fibrillary acidic protein; GALT: gut associated lymphoid tissues; H\&E: hematoxylin and eosin; HC: hippocampus; HMN: hypoglossal motor nucleus; Ht: hypothalamus; IHC: Immunohistochemistry; INL: inner nuclear layers; ITAS: intra-astrocytic; ITNR: intraneuronal; ITMG: intra-microglial; LFC: lateral frontal cortex; LINR: linear, "LSC: lumbar spinal cord; LRS: Iympho-reticular system; MO: medulla oblongata; Ms: mesencephalon; NFP: neuropilo fine punctate; nvCJD: new variant of Creutzfeldt-Jakob disease; NTN: nucleus of the trigeminal nerve spinal tract; OC: occipital cortex; ON: olivary nucleus; OD: optical density; ONL: outer nuclear layers; OPL: outer plexiform layer; PRCO: particulate/coalescing; PrPSC: pathological Prion Protein; PNER: perineuronal; PNS: peripheral nervous system; PVAC: perivacuolar; PVAS: perivascular; PS: photoreceptor layer; PRNP: prion protein gene coding; PrP: prion protein; PrPres: resistant prion protein; RF: reticular formation; RT: room temperature; Sh-BSE: sheep-bovine spongiform encephalopathy; SCJD: sporadic Creutzfeldt-Jakob disease; SBPL: subpial; TPC: temporal/parietal cortex; T: thalamus; TSC: thoracic spinal cord; TBM: tingible body macrophages; Tgpo: transgenic mice expressing porcine prion protein; TSE: transmissible spongiform encephalopathies.

\section{Competing interests}

The authors declare that they have no competing interests.

\section{Authors' contributions}

$\mathrm{CH}, \mathrm{HF}, \mathrm{BMa}, \mathrm{FC}, J \mathrm{LP}, \mathrm{OA}, \mathrm{FV}, \mathrm{RB}$, and JJB inoculated the animals. $\mathrm{CH}, \mathrm{HF}$, $\mathrm{BMa}$, JLP and $\mathrm{BMo}$ performed the clinical evaluations and necropsies. $\mathrm{CH}$ conducted the neuropathological studies. $\mathrm{CH}, \mathrm{RB}, \mathrm{OA}, \mathrm{CA}, \mathrm{AV}$, MP, and JJB participated in the design and drafting of the manuscript. $\mathrm{RB}$ and $\mathrm{JJB}$ coordinated the research. $\mathrm{CH}, \mathrm{RB}, \mathrm{MP}, \mathrm{OA}$ and JJB wrote the paper. All authors read and approved the final manuscript. 


\section{Acknowledgements}

This work was financed by the Fondo Europeo de Desarrollo Regional (FEDER), proyecto de Cooperación Transpirenaica en Seguridad de los Alimentos de Origen Ovino y Caprino (COTSA and ConCOTSA), Proyecto de Consolidación de la Cooperación Transpirenaica en materia de Seguridad Alimentaria EFA 282/13 (Transprion) and by the Government of Aragon. The authors also thank Silvia Castejón, Silvia Ruiz, Sonia Gomes and Nuria Segovia for their technical assistance.

\section{Author details}

${ }^{1}$ Veterinary Faculty, Centro de Investigación en Encefalopatías y Enfermedades Transmisibles Emergentes (CIEETE), Universidad de Zaragoza, 50013 Zaragoza, Spain. ${ }^{2}$ Veterinary Hospital, Universidad de Zaragoza, 50013 Zaragoza, Spain. ${ }^{3}$ Veterinary Faculty, Department of Animal Medicine and Surgery, Universitat Autònoma de Barcelona, 08193 Barcelona, Spain. ${ }^{4}$ UMR INRA ENVT 1225, Interactions Hôtes Agents Pathogènes, Ecole Nationale Vétérinaire de Toulouse, 31076 Toulouse, France.

Received: 15 May 2015 Accepted: 21 September 2015

Published online: 07 January 2016

\section{References}

1. Prusiner SB (1991) Molecular biology of prion diseases. Science 252:1515-1522

2. Budka H, Aguzzi A, Brown P, Brucher JM, Bugiani O, Gullotta F, Haltia M, Hauw JJ, Ironside JW, Jellinger K, Kretzschmar HA, Lantos PL, Masullo C, Schlote C, Tateishi J, Weller RO (1995) Neuropathological diagnostic criteria for Creutzfeldt-Jakob disease (CJD) and other human spongiform encephalopathies (prion diseases). Brain Pathol 5:459-466

3. Kim YS, Carp RI, Callahan S, Wisniewski HM (1990) Incubation periods and histopathological changes in mice injected stereotaxically in different brain areas with the $87 \mathrm{~V}$ scrapie strain. Acta Neuropathol 80:388-392

4. Fraser H (1979) The pathogenesis and pathology of scrapie. In: Tyrrell DAJ (ed) Aspects of slow and persistent virus infections, vol 2. Martinus \& Nijhoff, The Hague

5. Ironside JW, Sutherland K, Bell JE, McCardle L, Barrie C, Estebeiro K, Zeidler M, Will RG (1996) A new variant of Creutzfeldt-Jakob disease: neuropathological and clinical features. Cold Spring Harb Symp Quant Biol 61:523-530

6. Eloit M, Adjou K, Coulpier M, Fontaine JJ, Hamel R, Lilin T, Messiaen S, Andreoletti O, Baron T, Bencsik A, Biacabe AG, Beringue V, Laude H, Le Dur A, Vilotte JL, Comoy E, Deslys JP, Grassi J, Simon S, Lantier F, Sarradin P (2005) BSE agent signatures in a goat. Vet Rec 156:523-524

7. Jeffrey M, Martin S, Gonzalez L, Foster J, Langeveld JP, van Zijderveld FG, Grassi J, Hunter N (2006) Immunohistochemical features of PrPd accumulation in natural and experimental goat transmissible spongiform encephalopathies. J Comp Pathol 134:171-181

8. Spiropoulos J, Lockey R, Sallis RE, Terry LA, Thorne L, Holder TM, Beck KE, Simmons MM (2011) Isolation of prion with BSE properties from farmed goat. Emerg Infect Dis 17:2253-2261

9. Bellworthy SJ, Dexter G, Stack M, Chaplin M, Hawkins SA, Simmons MM, Jeffrey M, Martin S, Gonzalez L, Hill P (2008) Oral transmission of BSE to VRQNRQ sheep in an experimental flock. Vet Rec 162:130-131

10. Bellworthy SJ, Hawkins SA, Green RB, Blamire I, Dexter G, Dexter I, Lockey R, Jeffrey M, Ryder S, Berthelin-Baker C, Simmons MM (2005) Tissue distribution of bovine spongiform encephalopathy infectivity in Romney sheep up to the onset of clinical disease after oral challenge. Vet Rec 156:197-202

11. Foster JD, Hope J, Fraser H (1993) Transmission of bovine spongiform encephalopathy to sheep and goats. Vet Rec 133:339-341

12. Wells GA, Hawkins SA, Green RB, Austin AR, Dexter I, Spencer YI, Chaplin MJ, Stack MJ, Dawson M (1998) Preliminary observations on the pathogenesis of experimental bovine spongiform encephalopathy (BSE): an update. Vet Rec 142:103-106

13. Wells GA, Spiropoulos J, Hawkins SA, Ryder SJ (2005) Pathogenesis of experimental bovine spongiform encephalopathy: preclinical infectivity in tonsil and observations on the distribution of lingual tonsil in slaughtered cattle. Vet Rec 156:401-407

14. Foster JD, Bruce M, McConnell I, Chree A, Fraser H (1996) Detection of BSE infectivity in brain and spleen of experimentally infected sheep. Vet Rec 138:546-548

15. Espinosa JC, Herva ME, Andreoletti O, Padilla D, Lacroux C, Cassard H, Lantier I, Castilla J, Torres JM (2009) Transgenic mice expressing porcine prion protein resistant to classical scrapie but susceptible to sheep bovine spongiform encephalopathy and atypical scrapie. Emerg Infect Dis 15:1214-1221

16. Padilla D, Beringue V, Espinosa JC, Andreoletti O, Jaumain E, Reine F, Herzog L, Gutierrez-Adan A, Pintado B, Laude H, Torres JM (2011) Sheep and goat BSE oropagate more efficiently than cattle BSE in human PrP transgenic mice. PLoS Pathog 7:e1001319

17. Espinosa JC, Andreoletti O, Castilla J, Herva ME, Morales M, Alamillo E, San-Segundo FD, Lacroux C, Lugan S, Salguero FJ, Langeveld J, Torres JM (2007) Sheep-passaged bovine spongiform encephalopathy agent exhibits altered pathobiological properties in bovine-PrP transgenic mice. J Virol 81:835-843

18. Jahns H, Callanan JJ, Sammin DJ, McElroy MC, Bassett HF (2006) Survey for transmissible spongiform encephalopathies in Irish pigs fed meat and bone meal. Vet Rec 159:137-142

19. Wells GA, Hawkins SA, Austin AR, Ryder SJ, Done SH, Green RB, Dexter I, Dawson M, Kimberlin RH (2003) Studies of the transmissibility of the agent of bovine spongiform encephalopathy to pigs. J Gen Virol 84:1021-1031

20. Konold T, Spiropoulos J, Chaplin MJ, Thorne L, Spencer YI, Wells GA, Hawkins SA (2009) Transmissibility studies of vacuolar changes in the rostral colliculus of pigs. BMC Vet Res 5:35

21. Ryder SJ, Hawkins SA, Dawson M, Wells GA (2000) The neuropathology of experimental bovine spongiform encephalopathy in the pig. J Comp Pathol 122:131-143

22. Dawson M, Wells GA, Parker BN, Scott AC (1990) Primary parenteral transmission of bovine spongiform encephalopathy to the pig. Vet Rec 127:338

23. Heath CA, Barker RA, Esmonde TF, Harvey P, Roberts R, Trend P, Head MW, Smith C, Bell JE, Ironside JW, Will RG, Knight RS (2006) Dura mater-associated Creutzfeldt-Jakob disease: experience from surveillance in the UK. J Neurol Neurosurg Psychiatry 77:880-882

24. Priem J, Langeveld JPM, van Keulen LJM, van Zijderveld FG, Andreoletti O, Bossers A (2014) Enhanced virulence of eheep-passaged bovine spongiform encephalopathy agent is revealed by decreased polymorphism barriers in prion protein conversion studies. J Virol 88:2903-2912

25. Plinston C, Hart P, Hunter N, Manson JC, Barron RM (2014) Increased susceptibility of transgenic mice expressing human PrP to experimental sheep bovine spongiform encephalopathy is not due to increased agent titre in sheep brain tissue. J Gen Virol 95:1855-1859

26. Andreoletti O, Morel N, Lacroux C, Rouillon V, Barc C, Tabouret G, Sarradin P, Berthon P, Bernardet P, Mathey J, Lugan S, Costes P, Corbiere F, Espinosa JC, Torres JM, Grassi J, Schelcher F, Lantier F (2006) Bovine spongiform encephalopathy agent in spleen from an ARR/ARR orally exposed sheep. J Gen Virol 87:1043-1046

27. Monleon E, Monzon M, Hortells P, Vargas A, Acin C, Badiola JJ (2004) Detection of PrPsc on lymphoid tissues from naturally affected scrapie animals: comparison of three visualization systems. J Histochem Cytochem 52:145-151

28. Andreoletti O, Berthon P, Levavasseur E, Marc D, Lantier F, Monks E, Elsen JM, Schelcher F (2002) Phenotyping of protein-prion (PrPsc)-accumulating cells in lymphoid and neural tissues of naturally scrapie-affected sheep by double-labeling immunohistochemistry. J Histochem Cytochem 50:1357-1370

29. Gonzalez L, Martin S, Jeffrey M (2003) Distinct profiles of PrP(d) immunoreactivity in the brain of scrapie- and BSE-infected sheep: implications for differential cell targeting and PrP processing. J Gen Virol 84:1339-1350

30. Gonzalez L, Martin S, Houston FE, Hunter N, Reid HW, Bellworthy SJ, Jeffrey M (2005) Phenotype of disease-associated PrP accumulation in the brain of bovine spongiform encephalopathy experimentally infected sheep. J Gen Virol 86:827-838

31. Gonzalez L, Martin S, Begara-McGorum I, Hunter N, Houston F, Simmons M, Jeffrey M (2002) Effects of agent strain and host genotype on PrP 
accumulation in the brain of sheep naturally and experimentally affected with scrapie. J Comp Pathol 126:17-29

32. Vidal E, Acin C, Foradada L, Monzon M, Marquez M, Monleon E, Pumarola M, Badiola JJ, Bolea R (2009) Immunohistochemical characterisation of classical scrapie neuropathology in sheep. J Comp Pathol 141:135-146

33. Schaller O, Fatzer R, Stack M, Clark J, Cooley W, Biffiger K, Egli S, Doherr M, Vandevelde M, Heim D, Oesch B, Moser M (1999) Validation of a western immunoblotting procedure for bovine $\operatorname{Pr}(\mathrm{Sc})$ detection and its use as a rapid surveillance method for the diagnosis of bovine spongiform encephalopathy (BSE). Acta Neuropathol 98:437-443

34. Garza MC, Monzon M, Marin B, Badiola JJ, Monleon E (2014) Distribution of peripheral $\operatorname{PrP}(\mathrm{Sc})$ in sheep with naturally acquired scrapie. PLoS One 9:e97768

35. Goldmann W, Hunter N, Smith G, Foster J, Hope J (1994) PrP genotype and agent effects in scrapie: change in allelic interaction with different isolates of agent in sheep, a natural host of scrapie. J Gen Virol 75:989-995

36. Hunter N (1997) PrP genetics in sheep and the applications for scrapie and BSE. Trends Microbiol 5:331-334

37. Goldmann W, Martin T, Foster J, Hughes S, Smith G, Hughes K, Dawson M, Hunter N (1996) Novel polymorphisms in the caprine PrP gene: a codon 142 mutation associated with scrapie incubation period. J Gen Virol 77:2885-2891

38. Martin T, Hughes S, Hughes K, Dawson M (1995) Direct sequencing of PCR amplified pig PrP genes. BBA-Mol Basis Dis 1270:211-214

39. Lipp O, Ritzmann M, Kixmoller M, Heinritzi K, Hensel A, Truyen U (2004) Homogeneity of the prion protein gene in various European and Asian pig breeds. J Vet Med B Infect Dis Vet Public Health 51:97-98

40. Meng LP, Zhao DM, Liu HX, Yang JM, Ning ZY (2005) Single nucleotide polymorphisms of the prion protein gene (PRNP) in Chinese pig breeds. Xenotransplantation 12:324-326

41. Konold T, Bone G, Ryder S, Hawkins SA, Courtin F, Berthelin-Baker C (2004) Clinical findings in 78 suspected cases of bovine spongiform encephalopathy in Great Britain. Vet Rec 155:659-666

42. Forloni G, Delbo R, Angeretti N, Chiesa R, Smiroldo S, Doni R, Ghibaudi E, Salmona M, Porro M, Verga L, Giaccone G, Bugiani O, Tagliavini F (1994) A neurotoxic prion protein-fragment induces rat astroglial proliferation and hypertrophy. Eur J Neurosci 6:1415-1422

43. Giulian D, Lachman LB (1985) Interleukin-1 stimulation of astroglial proliferation after brain injury. Science 228:497-499

44. Lucassen PJ, Williams A, Chung WCJ, Fraser H (1995) Detection of apoptosis in murine scrapie. Neurosci Lett 198:185-188

45. Muhleisen H, Gehrmann J, Meyermann R (1995) Reactive microglia in Creutzfeldt-Jakob disease. Neuropath Appl Neuro 21:505-517

46. Liberski PP, Sikorska B, Wells GA, Hawkins SA, Dawson M, Simmons MM (2012) Ultrastructural findings in pigs experimentally infected with bovine spongiform encephalopathy agent. Folia Neuropathol 50:89-98

47. Sarasa R, Martinez A, Monleon E, Bolea R, Vargas A, Badiola JJ, Monzon M (2012) Involvement of astrocytes in transmissible spongiform encephalopathies: a confocal microscopy study. Cell Tissue Res 350:127-134

48. Greenlee JJ, Hamir AN, Greenlee MHW (2006) Abnormal prion accumulation associated with retinal pathology in experimentally inoculated scrapie-affected sheep. Vet Pathol 43:733-739

49. Hortells P, Monzon M, Monleon E, Acin C, Vargas A, Bolea R, Lujan L, Badiola JJ (2006) Pathological findings in retina and visual pathways associated to natural scrapie in sheep. Brain Res 1108:188-194

50. Valdez RA, Rock MJ, Anderson AK, O'Rourke KI (2003) Immunohistochemical detection and distribution of prion protein in a goat with natural scrapie. J Vet Diagn Invest 15:157-162

51. Spraker TR, Zink RR, Cummings BA, Sigurdson CJ, Miller MW, O'Rourke KI (2002) Distribution of protease-resistant prion protein and spongiform encephalopathy in free-ranging mule deer (Odocoileus hemionus) with chronic wasting disease. Vet Pathol 39:546-556

52. Hogan RN, Kingsbury DT, Baringer JR, Prusiner SB (1983) Retinal degeneration in experimental Creutzfeldt-Jakob disease. Lab Invest 49:708-715

53. Head MW, Northcott V, Rennison K, Ritchie D, McCardle L, Bunn TJR, McLennan NF, Ironside JW, Tullo AB, Bonshek RE (2003) Prion protein accumulation in eyes of patients with sporadic and variant CreutzfeldtJakob disease. Invest Ophthalmol Vis Sci 44:342-346

54. Jeffrey M, Martin S, Thomson JR, Dingwall WS, Begara-McGorum I, Gonzalez L (2001) Onset and distribution of tissue PrP accumulation in scrapie-affected suffolk sheep as demonstrated by sequential necropsies and tonsillar biopsies. J Comp Pathol 125:48-57

55. Fraser $\mathrm{H}$ (1982) Neuronal spread of scrapie agent and targeting of lesions within the retino-tectal pathway. Nature 295:149-150

56. Okada H, Iwamaru Y, Fukuda S, Yokoyama T, Mohri S (2012) Detection of disease-associated prion protein in the optic nerve and the adrenal gland of cattle with bovine spongiform encephalopathy by using highly sensitive immunolabeling procedures. J Histochem Cytochem 60:290-300

57. Hilbe MM, Soldati GG, Zlinszky KK, Wunderlin SS, Ehrensperger FF (2009) Immunohistochemical study of PrPSC distribution in neural and extraneural tissues of two cats with feline spongiform encephalopathy. BMC Vet Res 5:11

58. Seuberlich T, Zurbriggen A (2010) Distinct molecular signature of bovine spongiform encephalopathy prion in pigs. Emerg Infect Dis 16:164

59. McGovern G, Martin S, Jeffrey M, Bellworthy SJ, Spiropoulos J, Green R, Lockey R, Vickery CM, Thurston L, Dexter G, Hawkins SAC, Gonzalez L (2015) Influence of breed and genotype on the onset and distribution of infectivity and disease-associated prion protein in sheep following oral infection with the bovine spongiform encephalopathy agent. J Comp Pathol 152:28-40

60. Jeffrey M, Ryder S, Martin S, Hawkins SAC, Terry L, Berthelin-Baker C, Bellworthy SJ (2001) Oral inoculation of sheep with the agent of bovine spongiform encephalopathy (BSE). 1. Onset and distribution of disease-specific PrP accumulation in brain and viscera. J Comp Pathol 124:280-289

61. Hunter N, Houston F, Foster J, Goldmann W, Drummond D, Parnham D, Kennedy I, Green A, Stewart P, Chong A (2012) Susceptibility of young sheep to oral infection with bovine spongiform encephalopathy decreases significantly after weaning. J Virol 86:11856-11862

62. Siso S, Jeffrey M, Gonzalez L (2009) Neuroinvasion in sheep transmissible spongiform encephalopathies: the role of the haematogenous route. Neuropath Appl Neuro 35:232-246

63. Iwamaru $Y$, Imamura M, Matsuura Y, Masujin K, Shimizu Y, Shu YJ, Kurachi M, Kasai K, Murayama Y, Fukuda S, Onoe S, Hagiwara K, Yamakawa Y, Sata T, Mohri S, Okada H, Yokoyama T (2010) Accumulation of L-type bovine prions in peripheral nerve tissues. Emerg Infect Dis 16:1151-1154

64. Lezmi S, Ronzon F, Bencsik A, Bedin A, Calavas D, Richard Y, Simon S, Grassi J, Baron T (2006) PrPd accumulation in organs of ARQ/ARQ sheep experimentally infected with BSE by peripheral routes. Acta Biochim Pol 53:399-405

65. Hoffmann C, Ziegler U, Buschmann A, Weber A, Kupfer L, Oelschlegel A, Hammerschmidt B, Groschup MH (2007) Prions spread via the autonomic nervous system from the gut to the central nervous system in cattle incubating bovine spongiform encephalopathy. J Gen Virol 88:1048-1055

66. Okada H, Miyazawa K, Fukuda S, Iwamaru Y, Imamura M, Masujin K, Matsuura Y, Fujii T, Fujii K, Kageyama S, Yoshioka M, Murayama Y, Yokoyama $\mathrm{T}$ (2014) The presence of disease-associated prion protein in skeletal muscle of cattle infected with classical bovine spongiform encephalopathy. J Vet Med Sci 76:103-107

67. Lezmi S, Baron TG, Bencsik AA (2010) Is the presence of abnormal prion protein in the renal glomeruli of feline species presenting with FSE authentic? BMC Vet Res 6:41

\section{Submit your next manuscript to BioMed Central and we will help you at every step:}

- We accept pre-submission inquiries

- Our selector tool helps you to find the most relevant journal

- We provide round the clock customer support

- Convenient online submission

- Thorough peer review

- Inclusion in PubMed and all major indexing services

- Maximum visibility for your research

Submit your manuscript at www.biomedcentral.com/submit

C Biomed Central 